\title{
La fuerza política de la teoría del valor-escisión de Roswitha Scholz
}

\author{
The political strength of the labor theory \\ of value split of Roswitha Scholz
}

\begin{abstract}
Resumen: En esta ponencia se intenta resumir la teoría crítica del valor-escisión elaborada por Roswitha Scholz, que pretende presentar a capitalismo y patriarcado como sistemas inseparables. El valor-escisión delimitaría la esfera de lo productivo y lo público, e invisibiliza su necesaria relación con las actividades que no revalorizan capital pero son necesarias para la vida. Estas esferas corresponderían a lo masculino y lo femenino como atribuciones de género asignadas. Se intenta aplicar su teoría, principalmente centrada en lo económico, al ámbito político con ayuda de las tesis principales de Pierre Bourdieu.

Palabras clave: feminismo, capitalismo, Bourdieu, Scholz.
\end{abstract}

IRENE MARTÍNEZ DOMÍNGUEZ*

\begin{abstract}
This paper attempts to summarize the critical theory of value-split by Roswitha Scholz, which aims to introduce capitalism and patriarchy as inseparable systems. The value-split delimit the sphere of production and the public on, and it conceals its neccesary relation to activities that do not revalue capital, but they are necessary to the life. These areas correspond to the masculine and feminine as assigned gender duties. It tries to apply his theory, mainly focused on the economic, to the political area with the help of the capital theses of Pierre Bourdieu.
\end{abstract}

Keywords: feminism, capitalism, Bourdieu, Scholz.

\section{La teoría crítica del valor-escisión}

El desarrollo de las formas patriarcales parejo al desarrollo del capitalismo nos obliga a situarnos ante la evidencia de que el capitalismo no es una economía "socialmente neutra", tal y como parecía desprenderse para algunos movimientos sociales en general y movimientos feministas en particular, de la dinámica teorizada por Marx. A su vez, tampoco podemos esperar ya a que el patriarcado se vaya disolviendo, creyendo (y éste es el problema: creyendo) que el patriarcado es una institución residual, pre-capitalista y que irá desapareciendo con el avance global de este capitalismo pretendidamente neutro.

Fecha de recepción: 10/06/2016. Fecha de aceptación: 06/09/2016.

* Doctoranda de la Facultad de Filosofía de la Universidad Complutense de Madrid. Líneas de investigación: Bourdieu, feminismo, violencia obstétrica, violencia simbólica.Correo: iremarti@ucm.es 
Frente a esto, Roswitha Scholz intenta comprender el completo alcance de los conceptos básicos del capitalismo, presentándonos al patriarcado como esencial y funcional al mismo. Con ello, señala a algunos movimientos feministas por ser coadyuvantes de un reforzamiento del capitalismo -sin dejar de reconocer los derechos y libertades también adquiridos gracias a los mismos- al favorecer la invisibilización y consiguiente desconocimiento de no solo la connivencia sino la esencialidad del patriarcado con respecto al capitalismo y viceversa.

El reforzamiento del capitalismo por parte de movimientos feministas se debería a su negación a asumir la existencia de una contradicción irresoluble e indisociable entre capital y vida, base de nuestra sociedad capitalista, que afectaría a la totalidad de niveles de la sociedad: tanto a nivel socieconómico (en el que se centra Roswitha Scholz) como a un nivel sociopsicológico y simbólico-cultural. El problema del análisis hecho por los movimientos feministas que han acabado reforzando el capitalismo y, en algunos casos, podríamos decir que con él también el patriarcado derivaría de seguir utilizando conceptos marxistas, o incluso intentar expandirlos a nuevos ámbitos de aplicación relacionados con las tareas típicamente femeninas, sin que estén debidamente definidos, dejándonos llevar por la inercia de la utilización constante de dichos conceptos. La confusión principal surge, según Roswitha Scholz, en torno al término trabajo en el contexto capitalista. Se ha construido un concepto de trabajo entendido como una actividad antropológica de carácter transhistórico, definido por Himmeweilt como «una actividad con una finalidad, que consume tiempo y energía, forma parte de una división del trabajo y es separable de la persona que lo realiza» (como se cita en Abriales, 2013, p. 6). Es decir, se concibe el término trabajo en el capitalismo como la producción material de la propia existencia: con una utilidad y una finalidad intrínseca más allá del contexto concreto.

En cambio, el trabajo que nace con el capitalismo es una relación salarial situada, contextualizada y no transhistórica, enfocada a producir plusvalía, en una dinámica tautológica cuyo único fin es el beneficio, no ya individual, sino como piedra angular de todo el sistema económico. Podemos ejemplificarlo al observar cómo la misma actividad (por ejemplo, la del cuidado de niños/as) es considerada trabajo o no según sea asalariada o no y según valorice capital o no (si es un contrato mediado por una contrata valorizará directamente capital mientras que no lo hará si es un contrato directo entre los progenitores y la cuidadora). A su vez, este fin tautológico de la actividad trabajo es el que lleva a Marx a hablar de sujeto automático, como aquél que ha hecho mercancía de su propia fuerza de trabajo. De ahí puede derivar la confusión hacia un concepto de trabajo en el capitalismo como una actividad de carácter transhistórico, intentando algunos movimientos feministas (como el representado por Silvia Federici) expandir el término trabajo a otras esferas, como la reproducción, esenciales para la vida humana y por lo tanto para el desarrollo del capitalismo pero realmente no siempre posibles de clasificar como trabajo o no, como productiva o improductiva, por no implicar la mayoría de las veces una relación salarial ni revalorizar directamente capital.

Y aquí entramos en el otro concepto clave para el capitalismo como patriarcado productor de mercancías: el valor. El valor es el carácter social de este sistema productor de mercancías, la forma específica de riqueza en el capitalismo y este valor es un valor-escisión, que puede ser considerado valor porque se contrasta frente a algo: su escisión. Este valor produce, en palabras de Roswitha Scholz (2000), la «separación de cualidades, adjudicaciones y actividades específicas y típicamente "femeninas" que no pueden ser subsumidas a la forma del valor o la abstracción del "trabajo"». En el sistema capitalista pensado 
para el beneficio sin fin, el valor-escisión enfrenta una lógica del beneficio en el ámbito productivo a una lógica de los cuidados que regiría el ámbito de la vida; en un capitalismo que se basa en la temporización de nuestra vida (nuestro tiempo es oro para alguien, aunque no siempre para nosotros/as mismos/as), el valor-escisión enfrenta una lógica del ahorro de tiempo capitalista a una lógica del gasto del mismo en nuestras vidas.

Aún así, el valor-escisión, producción capitalista-vida, es una relación irresoluble e indisociable ya que, si el valor representa el núcleo del capitalismo (el valor del capital y su constante revalorización), su escisión representa la condición de posibilidad del mismo tanto por las tareas que se desarrollan en esa escisión del valor (reproducción de mano de obra, cuidados para la buena presencia necesaria en el puesto de trabajo, cariño para una estabilidad emocional necesaria para poder ser eficientemente productivo, etc.) como por la necesidad de que algo no sea valorado frente a lo que sí lo es para que tenga lugar el propio valor. Así, lo femenino es minusvalorado por ser femenino y aquello minusvalorado es femenino por ser minusvalorado.

\section{Valor-escisión, campos sociales e identidades}

La relación dialéctica valor-escisión ha derivado normalmente en la relación dialéctica entre ámbito de lo público y de lo privado. El ámbito de lo público recogería la producción capitalista, el trabajo, el valor y construiría la figura del hombre racional, competitivo, arriesgado, activo. Frente a ello, fuera de la lógica impuesta por el valor, el ámbito privado sería el ámbito del contenido sensible, de la reproducción; de la mujer como cuerpo, como supuesta naturaleza naturalizada (como diría Celia Amorós). El valor es creado por esa escisión que él mismo crea ${ }^{1}$.

Ante esto, hay que matizar varias cosas. Una de ellas, que Roswitha Scholz no pretende idealizar la escisión, criticando sólo el valor, idealizando en ese caso el ámbito privado como esfera natural carente de mediación. Al contrario, hace crítica del feminismo que ha idealizado lo tradicionalmente adjudicado como femenino, valorando lo concreto, lo sensible, la economía local y renuncia a lo demás: este feminismo, para Roswitha Scholz, sigue inmerso en la lógica del valor-escisión, en vez de hacer crítica del problema en su raíz.

Por otro lado, parece que se podría rebatir la teoría aludiendo a los individuos que han intercambiado sus papeles en estas esferas, haciendo referencia a las mujeres empresarias o a los papás encargados de cuidados. A pesar de esto, el valor-escisión seguiría imponiendo su lógica ya que las mujeres siguen encontrando en el ámbito productivo problemas como menores salarios o el conocido "techo de cristal" y muchos hombres son minusvalorados socialmente por el abandono de su tarea productiva y el desarrollo de actividades típicamente femeninas. Aún así, Roswitha Scholz insiste en el carácter dinámico de su teoría, que se

1 Muchos movimientos feministas critican ante esto que esa jerarquía hombre-mujer ya existía antes del capitalismo, por lo que no se puede ver construida por el mismo. En cambio, Roswitha Scholz recoge que en la sociedad pre-burguesa la influencia informal que podían llegar a tener las mujeres en política era mayor que cuando se construyó al hombre, más que como género, como valor simbólico de lo público. Del mismo modo, la vida agraria no implicaba ninguna escisión y la mujer trabaja codo a codo con el hombre. Evidentemente la mujer era minusvalorada, pero por ser una variante negativa del varón: era un sistema mono-género que se distancia por la polarización de los sexos llevada a cabo por la expansión del modelo de familia nuclear a todas las clases sociales. 
rehace con los cambios del capitalismo y del patriarcado, y que se encuentra en un meta nivel muy abstracto intentando ser una teoría total pero no totalizadora, es decir, no trata primeramente de individuos sino de estructuras y, además, no pretende someter a los individuos al análisis teórico, sino añadir el comportamiento de los mismos al perfeccionamiento de una teoría total. Citando a la autora:

Para los individuos empíricos, esto significa que no pueden sustraerse a los patrones socio-culturales de la cultura ni tampoco se agotan en ellos. Por otra parte, las representaciones de género están sometidas al cambio histórico (Scholz, 2013, p. 51).

Aún así, Roswitha Scholz se acerca al tema de las identidades de género, a las que reconoce que se les exige la univocidad propia para la presentación en la esfera pública de las mismas, generando así unas atribuciones por género que constituyen el orden simbólico de este capitalismo como patriarcado productor de mercancías. No por ello critica a la teoría Queer como generadoras de unas flexi-identidades, no unívocas en sus atribuciones de género, pero igualmente coactivas. Citando a la autora:

Estos movimientos consideran que la subversión interna del dualismo de género burgués a través de prácticas paródicas repetitivas, como se pueden encontrar en las subculturas gay y lésbica, ofrece una posibilidad de desacreditar radicalmente la identidad sexual moderna. Sin embargo el problema es que aquí la caricaturización desacredita algo que en sentido capitalista ya se ha vuelto obsoleto. Hace ya tiempo que se han producido "deconstrucciones reales", observables por ejemplo en la "doble socialización" de las mujeres, pero también en el vestir y en el comportamiento de hombres y mujeres, etc., sin que por ello haya desaparecido la jerarquía de género. En lugar de cuestionar las concepciones de género clásicamente modernas y las postmodernas modificadas o flexibilizadas, Butler se limita a confirmar la mala realidad postmoderna (de los géneros). (Scholz, 2013, p. 56)

Queda poco que añadir a esta cita: la teoría Queer no supone sino una reelaboración de identidades en el capitalismo como patriarcado productor de mercancías que mantiene el valor-escisión. A pesar de esto, puede pensarse y argumentarse que la opresión patriarcal con esto ha hecho la vida más habitable (como gusta decir a Judith Butler) pero, con la globalización actual, lo único que estamos viviendo es un embrutecimiento salvaje del patriarcado. Es cierto que las flexi-identidades de las que hablamos han permitido a individuos rechazar las atribuciones de género que les venían prefijadas, pero estas atribuciones, como el caso de la asistencia y los cuidados atribuidos a la mujer, sólo han sido redistribuidas dentro de los mundos femeninos, es decir, adjudicadas a empleadas del hogar, normalmente mujeres, normalmente migrantes y normalmente de clase baja. O, como en el caso de la industria textil, tarea también típificada como femenina, a mujeres sin recursos de países del así llamado tercer mundo, sometidos a una opresión patronal y patriarcal extrema.

Tampoco supone una panacea para las mujeres que disfrutan de esas flexi-identidades, que se suelen ver en situaciones de doble socialización, lo que comúnmente significa estar doblemente sobrecargadas, doblemente explotadas, y sin dejar de estar afectadas por estructuras 
patriarcales (como la paternidad despreocupada y desentendida de su progenie) y por viejas estructuras afectivas. Estas mujeres son reivindicadas por un tipo de feminismo sindical que las idealiza por la doble carga que pueden soportar, por la condición de doble explotada que puede sobrellevar. Un feminismo que exhibe la funcionalidad que tienen las mujeres en este capitalismo en crisis por el nivel de eficiencia que alcanza en condiciones verdaderamente desfavorables, y por estar acostumbradas psicológicamente a la precariedad, por lo que ésta afecta menos a su autoestima que a la de hombres acostumbrados a una carrera laboral lineal y estable. Dejando a un lado el hecho de que no parece apropiado para el feminismo reivindicar a la mujer como mula de carga, este feminismo se sigue colocando dentro del valor-escisión, defendiéndolo de hecho, y siendo coadyuvante de su mayor desarrollo.

Por otro lado, una apuesta por este tipo de contraposiciones al estado actual de las cosas que sea sólo individual, supone un riesgo elevado frente a los pocos beneficios que se pueden conseguir: tal y como comentará Bourdieu en La dominación masculina, sólo la actividad colectiva puede llevar a un cambio social real, efectivo y duradero.

\section{El Estado o el ámbito político}

Aunque Roswitha Scholz analiza principalmente el ámbito socioeconómico, como hemos visto, nos da apuntes para la aplicación de su teoría en el ámbito político. Así, nos habla de la existencia de alianzas masculinas que se basan en la aversión a lo femenino y lo contextualiza añadiendo que «todo el Estado y la política están constituidos desde el siglo XVIII sobre los principios de libertad, igualdad y fraternidad como alianzas masculinas» (Scholz, 2013 , p. 53). Una afirmación quizá desconcertante hasta que nos paramos a pensar para quién era la igualdad y la libertad y quién entraba en la fraternidad (¿a quién se defiende en las guerras y qué cuerpos, por el contrario, se colonizan?): las mujeres sólo se encuentran en este Estado, en esta política y en el contrato social instaurador en términos de subalternas (en esto no entraremos ya que, aparte de una cuestión de tiempo, ha sido bien analizado por los estudios postcoloniales, Spivak entre otras autoras).

La mujer para la política actual sigue siendo sólo cuerpo. A la mujer se le presupone una naturaleza que hay que preservar en base a un logos que a ella se le niega. Es naturaleza porque así lo preescribe la naturaleza (el deber ser). Por ello, se presupone, por ejemplo, su instinto maternal mientras se legisla como si, por ellas fuera, todas fueran a optar por una Interrupción Voluntaria del Embarazo; en palabras de Amorós (2014, p. 37) «en el fondo se piensa que las excelsas madres por instinto son unas zorras». A la mujer se la legisla como incapaz de autonormarse, como cuerpo irracional, capaz de gestar pero no de gestionar. Se legisla desde el ámbito político, público, masculino y la escisión femenina, improductiva, irracional, sólo puede ser legislada: el orden simbólico patriarcal es generado por ese valorescisión, que da lugar a legislaciones denigrantes que infantilizan a la mujer.

El Estado es una banca de bienes simbólicos, el que instituye y legitima el orden simbólico. Ese campo burocrático que sería el Estado genera disposiciones específicas para el éxito o no en ese campo. Aunque es cierto que la búsqueda de un mayor éxito en dicho campo es opcional (optar a ser funcionariado es una elección propia), todos/as somos partícipes en mayor o menor medida del campo burocrático. Impuestos, declaraciones de la renta, reconocimiento de la ciudadanía, sanidad pública, educación pública...todos estos ámbitos, algunos de obli- 
gado cumplimiento, exigen unas disposiciones específicas para garantizar el triunfo en cada uno de ellos. Para adquirir estas disposiciones, es necesario cierto grado de conocimiento y reconocimiento del campo en cuestión y de la disposición de relaciones jerárquicas o no dentro del mismo (por poner un ejemplo, que probablemente desvirtúe los matices de lo expuesto, es obvio que el contribuyente debe reconocer al funcionariado público que puede efectuar su declaración de la renta y por ello les da el poder sobre sus datos financieros).

Roswitha Scholz nos define el fetichismo como «la alienación de los miembros de la sociedad, pues su propia socialidad se constituye a través de sus productos, esto es, a través de cosas muertas, desvinculadas en la forma de representación social de cualquier contenido concreto y sensorial» (Scholz, 2013, 47). Esto nos conecta con el fetichismo del delegacionismo del que nos habla Bourdieu (1996): el representante político de un grupo es un fetiche para el propio grupo. El grupo social dominado sólo existe en el plano político, público, real, gracias a la representación que el representante hace de él. El representante, que no sería tal sino fuera por el grupo, se convierte en cambio en la condición de posibilidad del mismo. Entrar en la esfera pública, política, masculina, exige un conocimiento y reconocimiento de sus disposiciones y dinámicas y asumir cierta disposición en el mismo que debe ser racional, unívoca (de ahí la necesidad de un representante), eliminándose lo concreto, lo sensorial, la vida y todo lo que no presente unidad.

La esfera de la escisión, de la vida, de lo concreto, de lo atribuido a lo femenino, se habría perdido en su camino por hacerse real, por presentarse en el plano de la realidad, aceptando la lógica del valor-escisión. De nuevo esta opción, como otras ya mencionadas, supone seguir en la inmanencia del valor-escisión.

Destruir la jerarquía de género implica destruir el capitalismo y la política tal y como es entendida ahora: como jerárquica y exclusivamente racional, alejada de la vida. Es decir, destruir la jerarquía de género implica destruir el valor-escisión, poner la vida en el centro y no el beneficio por el beneficio como lógica económica y social, hacer política horizontal y no jerárquica, con representación por cuestiones prácticas pero no con delegación de decisiones (lo cual implica jerarquía y la asunción de la propia inmadurez e incapacidad de autogobierno); hacer política desde el cuerpo, que implica la razón pero también lo sensorial, que es abierto a lo concreto y a lo múltiple.

\section{Obras citadas}

Abriales, Álvaro (2013): “El patriarcado productor de mercancías”: la teoría del valorescisión de Roswitha Scholz, comunicación al IV CONGRESO DE ECONOMÍA FEMINISTA, 2013, Carmona (Sevilla).

Amorós, Celia (2014): Salomón no era sabio, Editorial Fundamentos, Madrid.

Bourdieu, Pierre (1996): "La delegación y el fetichismo político", en Cosas dichas, Gedisa.

Scholz, Roswitha (2000): ¡Fuera holgazanas! Sobre la relación de género y trabajo en el feminismo, disponible en <http://obeco.planetaclix.pt/rst.htm>.

Scholz, Roswitha (2013): El patriarcado productor de mercancías. Tesis sobre capitalismo y relaciones de género, en Revista Constelaciones, Número 5 (Diciembre de 2013), pp. 44-80. 